\title{
Effects of Conceptual Knowledge and Availability of Information Sources on Law Students Legal Reasoning
}

Citation for published version (APA):

Nievelstein, F., Van Gog, T., Boshuizen, E., \& Prins, F. (2010). Effects of Conceptual Knowledge and Availability of Information Sources on Law Students Legal Reasoning. Instructional Science, 38(1), 23-35.

https://doi.org/10.1007/s11251-008-9076-3

DOI:

$10.1007 / \mathrm{s} 11251-008-9076-3$

Document status and date:

Published: 01/01/2010

Document Version:

Peer reviewed version

Document license:

CC BY-NC

Please check the document version of this publication:

- A submitted manuscript is the version of the article upon submission and before peer-review. There can be important differences between the submitted version and the official published version of record. People interested in the research are advised to contact the author for the final version of the publication, or visit the DOI to the publisher's website.

- The final author version and the galley proof are versions of the publication after peer review.

- The final published version features the final layout of the paper including the volume, issue and page numbers.

Link to publication

\section{General rights}

Copyright and moral rights for the publications made accessible in the public portal are retained by the authors and/or other copyright owners and it is a condition of accessing publications that users recognise and abide by the legal requirements associated with these rights.

- Users may download and print one copy of any publication from the public portal for the purpose of private study or research.

- You may not further distribute the material or use it for any profit-making activity or commercial gain

- You may freely distribute the URL identifying the publication in the public portal.

If the publication is distributed under the terms of Article 25fa of the Dutch Copyright Act, indicated by the "Taverne" license above, please follow below link for the End User Agreement:

https://www.ou.nl/taverne-agreement

Take down policy

If you believe that this document breaches copyright please contact us at:

pure-support@ou.nl

providing details and we will investigate your claim.

Downloaded from https://research.ou.nl/ on date: 26 Apr. 2023 


\title{
Effects of conceptual knowledge and availability of information sources on law students' legal reasoning
}

\author{
Fleurie Nievelstein, Tamara van Gog, Henny P. A. Boshuizen, \& Frans J. Prins
}

\begin{abstract}
Due to the complexity of the legal domain, reasoning about law cases is a very complex skill. For novices in law school, legal reasoning is even more complex because they have not yet acquired the conceptual knowledge needed for distilling the relevant information from cases, determining applicable rules, and searching for rules and exceptions in external information sources such as lawbooks. This study investigated the role of conceptual knowledge in solving legal cases when no information sources can be used.

Under such 'unsupported' circumstances, novice and advanced students performed less well than domain experts, but even experts' performance was rather low. The second question addressed was whether novices even benefit from the availability of information sources (i.e., lawbook), because conceptual knowledge is prerequisite for effective use of such sources. Indeed availability of the lawbook positively affected performance only for advanced students but not for novice students. Implications for learning and instruction in the domain of law are discussed.
\end{abstract}

Keywords Higher eduction__Conceptual knowledge _ Information sources _ Reasoning_ Novices_Experts__ognitive load

\section{Introduction}

Reasoning about cases is a key component of the legal profession, and consequently, of legal education. Legal reasoning is a complex cognitive skill (Stratman, 2002), and this complexity results mostly from the characteristics of the legal domain (Blasi, 1995). The legal domain differs from other domains such as medicine or engineering in that during task performance, professionals have to rely heavily on information sources, that is, books of reference such as lawbooks and jurisprudence (Sullivan et al., 2007; Williams, 1992).

Consequently, the preferred method of instruction for learning to reason about law cases, is working on cases with the aid of the external information sources professionals in law would use. We argue here, however, that it is questionable whether this method of instruction is the most optimal one, especially for novice students, because they lack correct conceptual knowledge (Blasi, 1995; Deegan, 1995; Lindahl, 2004; Nievelstein et al., in press), which is needed to understand-and reason aboutcases and external information.

This study investigates the role of availability of conceptual knowledge in two ways. First by looking at how expertise influences reasoning about a case when no information sources are available. Second, it is investigated whether the availability of information sources actually helps students, especially novices, in solving legal cases. Before going into detail about the role that conceptual knowledge and information sources play in legal reasoning, we will first shortly describe commonalities and differences in legal reasoning between the Common Law and Civil Law systems.

\section{Common vs. civil law}

Despite differences between the systems, reasoning about legal cases is a complex skill both in Common Law (Anglo-Saxon) and Civil Law (European-Continental; Vandevelde, 1996). To reason about legal problems in Common Law, lawyers rely heavily on applying jurisprudence, that is, on solving cases by analogy (Marchant et al., 1993). The structural characteristics (relevant legal facts and context) of a current case should be compared and contrasted with structural features of prior relevant cases to infer whether the same conclusion could be drawn (Aamodt \& Plaza,1994). In high court, a present case always has to be decided according to a past case judgement. In lower court, judges have the right to decide alternatively (Marchant et al., 1993; Vandevelde, 1996). Analogical case-based reasoning also plays a role in the Civil Law system, but less pronounced. In Civil Law, legal reasoning relies more heavily on interpretation and application of codified legal rules to cases (Stratman, 2004). The legal rules are codified for different law domains, such as in the civil code or the commercial code. Judges decide cases primarily based on the rules, but when the codes and statutes cannot give a decisive answer about the judgement on a legal problem, judges have to base their decision on similar past cases (Vandevelde 1996). However, both in Common Law and in Civil Law, 
conceptual knowledge and the use of information sources (i.e., jurisprudence or codes) play a key role in reasoning about cases.

The role of available conceptual knowledge and information sources in legal reasoning

\section{Conceptual knowledge}

Having correct conceptual knowledge is prerequisite for correct legal reasoning (Deegan, 1995; Lindahl, 2004; Lundeberg, 1987; Williams, 1992). First of all, conceptual knowledge is required to understand the legal problem, that is, to decide what information in a particular case is important and what is redundant (i.e., irrelevant). Second, it is necessary to decide what kind of rules or jurisprudence should be searched for, and to interpret and apply these correctly. Nievelstein et al. (in press) showed that novices and advanced students had less formal and less shared knowledge about legal concepts and the relations between those concepts than law experts. Formalized shared knowledge is referred to as the ontology of the domain (Bench-Capon \& Visser, 1997; Chi \&, Roscoe 2002). The acquisition of correct conceptual knowledge is a difficult process in many domains, because many concepts that are routinely used in everyday language have a different formal meaning (see e.g., Slotta \& Chi, 2006). This also occurs very often in the legal domain (see e.g., Lindahl, 2004; Lundeberg, 1987). The findings of Nievelstein et al. also showed that novice students provided naïve and fragmented elaborations of concepts using mostly everyday language. In addition, there was hardly any shared knowledge within their group (i.e., individual knowledge about legal concepts differed enormously). Advanced students had more correct conceptual knowledge, used fewer daily examples, and used more formal legal language than novices, but they did not yet show much shared knowledge either.

\section{Information sources}

In solving legal problems, practitioners have to rely on information sources such as databases containing jurisprudence, or codes and statutes (Williams, 1992), because every case judgment should be defined precisely (i.e., based on books of reference) in such a way that the judgment can be inferred exactly by others engaged in the legal process (Sullivan et al., 2007). Existing jurisprudence, the exact meaning of rules, and exceptions on rules can be looked up at any time in order to check or substantiate argumentation. However, next to knowledge of how these information sources are organized, conceptual knowledge is also necessary to make effective use of these information sources (Williams, 1992), that is, to find the right rules or jurisprudence, understand this information, and link it to the case.

\section{Legal reasoning}

In problem solving, including solving legal cases, a number of general problem-solving phases can be distinguished (cf., Veenman \& Elshout, 1995). Orientation on the problem/ case (i.e., framing the problem), planning (e.g., what steps, and in which order, should I take to solve the problem?), executing (e.g., elaborating on a problem/case and drawing conclusions), monitoring the problem solving process (i.e., in-between evaluations, e.g., am I still on the right track, on time?), and finally evaluating the entire process and the final product (e.g., how did I do overall?). Orientation, planning, monitoring and evaluating can be seen as regulation phases whereas the executing phase consists of elaborating on the problem and drawing conclusions. There is no fixed order through these phases, and phases can be revisited. Expertise seems to influence the amount and duration of engagement in these general processes. In law for example, Lundeberg (1987), compared novices' (i.e., non-lawyers) and experts' approaches of case reading. During case reading, more experts than novices used general strategies; they put the case into context, made an overview, reread, underlined, synthesized and evaluated information from the case. Oates (2006) also showed that during case reading a law professor summarized and evaluated information from the case more often than law students did. In legal reasoning, the execution phase consists mainly of elaborating arguments and drawing conclusions on claims regarding applicability of rules. According to Toulmin's model of argument, elaborating arguments and drawing conclusions can be subdivided into six different steps: (1) grounds, (2) warrants, (3) backings, (4) rebuttals, (5) qualifiers, and (6) conclusions (Toulmin et al., 1984; see also Vandevelde, 1996). For instance, in solving a legal case, a lawyer must first distinguish and extract the legally relevant facts (grounds) from the case information. Based on the relevant facts, applicable sources of law referred to as warrants (e.g., rules of law and statutes) have to be identified, along with possible additional information like a reference to generally accepted knowledge, norms or jurisprudence, which can strengthen the warrant (i.e., backings). These warrants and backings have to 
be compared to the grounds to test whether rules are indeed applicable to these facts. Applicable rules of law have to be placed in a specific sequence in which the more specific rules will be tested after the more general rules have proven valid. Rebuttals are information elements from the case that require the application of exceptions on rules, and the qualifier reflects the probability of a legally correct conclusion on the basis of the available grounds, warrants, backings and rebuttals. The final conclusion (i.e., judgment) should be drawn, consisting of that which, based on available information, can be asserted.

\section{The present study}

The present study addresses how the availability of conceptual knowledge and information sources affects the process and quality of legal reasoning in the Civil Law (European-Continental) system. The first question investigated here concerns the role of conceptual knowledge in legal reasoning. In order to study this question, we compared novices and advanced students with experts in an 'unsupported' condition, in which they could not rely on information sources. Because in practice, legal professionals can always rely on information sources when working on cases, it is unclear to what extent they depend on these sources, and to what extent their acquired conceptual knowledge (i.e., their expertise) can help them solve a case. It is hypothesized that: (1) students (novice and advanced) will be less accurate in solving a legal case than experts, and (2) because students have much less conceptual knowledge than experts, we expect differences in the problem-solving process, with students showing less regulation and execution activities than experts.

Probably because legal professionals rely on information sources when solving cases, the preferred method of instruction is having students solve cases with the aid of such sources. However, we argue that even under such 'natural' conditions where students can make use of information sources, it is questionable whether this can help novice students, because adequate use of these sources would also rely on conceptual knowledge, as well as on knowledge of how the source is organized. Lack of such knowledge would probably result in ineffective search strategies when using the information source, which imposes a heavy additional load on working memory (cf. Sweller et al., 1998), thereby reducing the cognitive resources available for reasoning about the case. That is, when a student does not know exactly what (s)he is looking for, or does not know where to look for that information, the search space becomes very large and students may get 'lost' in the search process itself. Consequently, given the limited capacity of quantity and duration of working memory (see Miller, 1956; Cowan, 2001), it will be difficult if not impossible tokeep the case details active in working memory, let alone linking possibly relevant information to the case.

Therefore, the second question addressed here is whether novice students can benefit from the availability of an information source (in this study: the civil code). It is hypothesized that: (3a) novices allowed to use the civil code would not be more accurate in solving the legal case compared to novices who are not allowed to use it, whereas ( $3 \mathrm{~b}$ ) advanced students who are allowed to use the civil code, would be more accurate in solving the legal case than advanced students who are not allowed to use this source, because contrary to novices, they have sufficient (conceptual) knowledge to find and benefit from the information in the civil code (i.e., they can understand and apply the information). Furthermore, (4) both novices and advanced students' general problem-solving process will be affected by the use of an external source. Those who have more information at their disposal, will show more regulation and execution activities than those advanced and novice students who were not allowed to use the civil code.

\section{Method}

Participants

Forty-eight students enrolled in civil law courses (Dutch specification: 'privaatrecht') and 12 staff members specialized in civil law participated in this study. Students were 24 first year students (novices) who recently completed an introductory course on civil law, and 24 third-year students (advanced students) who additionally completed two more extensive civil law courses. The 12 members of the faculty of law had on average 5.9 years of experience with civil law after obtaining their $\mathrm{PhD}$ (experts). Students received a financial compensation of $€ 10$ (ca. \$14 at the time of writing) for their participation, and experts received a present of about the same amount of money, but were not informed about this in advance.

\section{Design}

There are three expertise groups: novices, advanced students, and experts. The novice and advanced 
students were randomly assigned to a condition in which they could or could not use an information source (i.e., the civil code). This resulted in five conditions: novices without civil code $(\mathrm{n}=12)$, novices with civil code $(n=12)$, advanced students without civil code $(n=12)$, advanced students with civil code $(n=12)$, and experts (without civil code; $n=12$ ).

Materials

Case

A Civil law case printed on A4 paper. This case concerned law of obligations and described a conflict between two civilians (the plaintiff, Mr. S., and the defendant, Mr. D.) about the ownership and the garaging of a sailing boat. Based on the context, five legal claims were described (i.e., right of reclamation, right of retention, costs of garaging, finder's reward, and legal costs; see Appendix A).

\section{Civil code}

In the civil code (Klomp \& Mak, 2005) statutes and rules, applicable in civil procedures, are codified.

\section{Think-aloud instruction and recording}

Participants were instructed to argue on the case from the perspective of the defendant's lawyer, and while doing so, to think aloud, that is, to verbalize everything that came to their mind without any restrictions (Ericsson \& Simon, 1993). Their verbalizations were directly recorded on a laptop computer with Audacity 1.2.4b audio editor, using a microphone.

\section{Procedure}

The experiment was run in individual sessions. Participants were given a maximum time of 30 min to work on the case. First, they were instructed to read the case aloud for up to $5 \mathrm{~min}$. After reading the case, participants were instructed to analyse the case from the perspective of the defendant's lawyer, and to give an elaborate description of how they would solve the problem in the specific case. Students in the conditions with civil code received the additional instruction that they could use the civil code on their desk at any time. In case participants stopped thinking aloud, the experimenter prompted them after about $5 \mathrm{~s}$ by saying that they should continue to think aloud. The recorded verbalizations were transcribed after the experiment.

Data analysis

\section{Reasoning process}

The coding scheme used to analyse the think-aloud protocols in terms of general problem solving processes was based on the one used in a pilot study by Nievelstein et al. (2005), and was further refined with a subset of protocols from the present study. The problem solving process was categorized by four main regulative categories, that is, Orientation, Planning, Monitoring, and Evaluating, and by two main executive categories, Elaborating and Concluding. Orientation was subdivided into problem orientation (e.g., reading aloud, summarizing, perspective taking, labeling, making assumptions, and identifying knowledge gaps), and into activating domain knowledge (e.g., using conceptual knowledge, using the civil code). Planning concerned remarks about the steps one would or should take to solve the problem. Monitoring concerned in-between evaluations of the problem solving process, whereas evaluations about the final product fell in the category Evaluating. The categories Elaborating and Concluding comprised arguments or conclusions, respectively, with regard to one of the five claims mentioned in the case.

The protocols were segmented and coded based on meaning, that is, parts of the protocol that could be assigned as a whole to one of the categories, were coded as one segment. Two raters independently scored $25 \%$ of the protocols. The inter-rater reliability was 0.81 (Cohen's kappa). Because this interrater reliability was high (0.70 is considered sufficient; Van Someren et al., 1994) the remaining protocols were scored by one rater. Our analysis was based on the total number of codes per problemsolving process category (i.e., the frequencies). The process of segmentation and coding was done with the software program Multiple Episode Protocol Analysis (MEPA; Erkens, 2002). 
To investigate the quality of the argumentations (i.e., the parts of the protocol that were coded as belonging to the executive process categories of "elaborating" and "concluding"), a coding scheme based on Toulmin's Model of Argument (Toulmin et al., 1984) was used, which was also tested in the pilot study by Nievelstein et al. (2005). This coding scheme consisted of five out of the six categories: grounds, warrants, backings, rebuttals and the final conclusion. We decided to exclude the qualifying category because a qualified would reflect the participants' subjective certainty of the accuracy of the answer, which is more of a regulative statement, and would therefore fall in the Monitoring or Evaluation categories.

Per claim mentioned in the case, elaborations and conclusions given by the participants were expounded in Toulmins' model of argument to reveal completeness of reasoning. The relevant judicial case information regarding to one of the five claims can be seen as the ground on which arguments and/or conclusions could be based. First the grounds described in the case (i.e., maximum five) identified by participants, were counted. Parts of the protocol that belonged to the categories of elaborating (i.e., argumentation) and concluding were coded per legal claim as being either a warrant, conclusion, backing or rebuttal. The accuracy of those warrants, conclusions, backings and rebuttals was rated according to an answer model (cf. those used by teachers to grade case elaborations solutions on tests or exams) that contained detailed elaborations of the five claims based on the descriptions of the five claims in the Dutch civil code. For every correct warrant, conclusion, backing and rebuttal, consistent with the answer model, 1 point was scored. In total 24 points could be assigned.

\section{Results and discussion}

The means and standard deviations regarding the accuracy of reasoning, are shown in Table 1, those regarding the reasoning process are shown in Table 2.

Table 1 The means and standard deviations of reasoning accuracy scores of novice students, advanced students and experts

\begin{tabular}{|c|c|c|c|c|c|c|c|c|c|c|}
\hline & \multicolumn{4}{|c|}{ Novice students } & \multicolumn{4}{|c|}{ Advanced students } & \multicolumn{2}{|c|}{ Experts } \\
\hline & \multicolumn{2}{|c|}{ No code } & \multicolumn{2}{|l|}{ Code } & \multicolumn{2}{|c|}{ No code } & \multicolumn{2}{|c|}{ Code } & & \\
\hline & $\mathrm{M}$ & SD & M & SD & $\mathrm{M}$ & SD & $\mathrm{M}$ & SD & $\mathrm{M}$ & SD \\
\hline $\begin{array}{l}\text { Correct total } \\
\text { warrants }\end{array}$ & 2.42 & 1.62 & 1.83 & 1.12 & 1.42 & 1.00 & 2.92 & 1.44 & 3.42 & 1.62 \\
\hline $\begin{array}{l}\text { Correct total } \\
\text { backings }\end{array}$ & 0.50 & 0.80 & 1.50 & 1.73 & 0.50 & 0.79 & 1.00 & 1.71 & 1.67 & 1.37 \\
\hline $\begin{array}{l}\text { Correct total } \\
\text { rebuttals }\end{array}$ & 0.17 & 0.39 & 0.08 & 0.30 & 0.08 & 0.29 & 0.42 & 0.79 & 0.33 & 0.49 \\
\hline $\begin{array}{l}\text { Correct total } \\
\text { conclusions }\end{array}$ & 1.50 & 1.62 & 2.17 & 0.72 & 1.25 & 1.36 & 2.33 & 1.23 & 2.33 & 1.37 \\
\hline $\begin{array}{l}\text { Correct total } \\
\text { elements }\end{array}$ & 4.58 & 3.60 & 5.58 & 2.99 & 3.25 & 2.53 & 6.67 & 4.66 & 7.75 & 3.75 \\
\hline
\end{tabular}

Table 2 Means and standard deviations of reasoning process scores of novice students, advanced students and experts

\begin{tabular}{|c|c|c|c|c|c|c|c|c|c|c|}
\hline & \multicolumn{4}{|c|}{ Novice students } & \multicolumn{4}{|c|}{ Advanced students } & \multicolumn{2}{|c|}{ Experts } \\
\hline & \multicolumn{2}{|c|}{ No code } & \multicolumn{2}{|l|}{ Code } & \multicolumn{2}{|c|}{ No code } & \multicolumn{2}{|l|}{ Code } & & \\
\hline & $\mathrm{M}$ & SD & $\mathrm{M}$ & SD & $\mathrm{M}$ & SD & $\mathrm{M}$ & SD & $\mathrm{M}$ & SD \\
\hline $\begin{array}{l}\text { Mean total } \\
\text { protocol } \\
\text { elements }\end{array}$ & 33.00 & 18.17 & 50.83 & 21.05 & 30.67 & 10.65 & 46.25 & 25.63 & 36.92 & 15.06 \\
\hline $\begin{array}{l}\text { Total number } \\
\text { regulative } \\
\text { phases }\end{array}$ & 14.75 & 8.76 & 34.25 & 13.31 & 17.42 & 9.47 & 28.67 & 23.90 & 20.75 & 11.52 \\
\hline $\begin{array}{l}\text { Total number } \\
\text { executive phases }\end{array}$ & 18.25 & 11.54 & 16.58 & 11.41 & 13.25 & 4.69 & 17.58 & 10.98 & 16.17 & 9.24 \\
\hline $\begin{array}{l}\text { Orientation } \\
\text { (reg) }\end{array}$ & 11.08 & 8.63 & 24.25 & 10.10 & 11.42 & 6.75 & 20.33 & 16.99 & 15.33 & 8.91 \\
\hline Monitoring (reg) & 0.92 & 0.52 & 4.33 & 3.23 & 0.92 & 1.17 & 3.33 & 3.47 & 2.25 & 2.63 \\
\hline
\end{tabular}




\begin{tabular}{|l|r|r|r|r|r|r|r|r|r|r|}
\hline Planning (reg) & 2.08 & 1.38 & 3.92 & 1.78 & 3.25 & 2.53 & 3.33 & 3.31 & 1.92 & 2.02 \\
\hline Evaluation (reg) & 0.67 & 0.49 & 1.75 & 2.49 & 1.83 & 1.34 & 1.67 & 1.72 & 1.25 & 1.42 \\
\hline $\begin{array}{l}\text { Elaboration } \\
\text { (exe) }\end{array}$ & 11.25 & 6.90 & 10.25 & 8.60 & 8.42 & 3.66 & 11.33 & 7.38 & 9.58 & 5.47 \\
\hline Concluding (exe) & 7.00 & 4.99 & 6.33 & 3.55 & 4.83 & 1.70 & 6.25 & 4.00 & 6.58 & 4.44 \\
\hline
\end{tabular}

Effects of availability of conceptual knowledge

\section{Accuracy of reasoning}

In line with our first hypothesis, a planned contrast showed that students were less accurate than experts, that is, the sum of the correct warrants, backings, rebuttals and conclusions for the five different claims in the case, was significantly lower for students $(M=3.92, S D=3.13)$, than for experts $(\mathrm{M}=7.75, \mathrm{SD}=3.75), \mathrm{t}(55)=3.02, \mathrm{p}<0.05, \mathrm{~d}=1.11$.

The following excerpts from a student's and an expert's protocol illustrate their elaborations on the claim 'right of retention'. Student: 'Well the right of retention I think that it never existed at all. I do not know exactly why because I do not exactly know what the right of retention means...' Expert: 'Mr D is still the owner of the sailing boat, Mr S cannot claim that he is the owner because Mr S took charge of the sailing boat so he did not become the owner. Mr S should have required an ownership certificate of the sailing boat. Well, let's see. The right of retention existed until the police took possession of the sailing boat...'

However, experts' mean score was not very high: on average, they scored only 7.25 out of 24 points. One might suppose that this score reflects that experts might be able to draw adequate conclusions, but might depend on a lawbook to provide the exact argumentation, but that was not the case, because a closer look at the accuracy scores shows that experts' mentioned only $47 \%$ of the correct conclusions, and $30 \%$ of the of the correct argumentation elements according to the coding scheme (i.e., warrants, backings, rebuttals).

Therefore, this finding suggests that experts do not only rely on the use of information sources for substantiating their conclusions, but also for drawing them. This is probably because law professionals routinely use information sources when they are working on cases in everyday practice (Williams, 1992). Without having access to those sources, they experience difficulties applying the formal law properly. A quote from an expert protocol can illustrate this. 'Well, this specific problem is more or less similar to a decree I know...Hmm, the easiest way to solve this case is to search for this decree...but that is not possible now...' Another expert mentioned: 'First I should search in the code what specifically is said about ownership and depository...'

\section{Reasoning process}

Contrary to our expectations, a planned contrast showed no significant differences between students and experts on regulation activities: $\mathrm{t}(55)=-0.91$, $\mathrm{ns}$, and execution activities: $\mathrm{t}(55)=-0.12$, ns. The fact that experts and students did not differ significantly with regard to their problem solving processes (as the studies of Lundeberg ,1987, and Oates, 2006, would suggest), might also be a consequence of not being allowed to use information sources, which may have interfered with their usual approach to problem solving.

Effects of availability of an information source on students' reasoning

\section{Accuracy of reasoning}

In line with our hypothesis, planned contrasts showed that advanced students who could use the civil code were significantly more accurate than advanced students who could not use the civil code, $t(55)$ $=-2.33, \mathrm{p}<0.05, \mathrm{~d}=0.13$, whereas no significant difference was found for novices $\mathrm{t}(55)=-0.74$, ns. We hypothesized that this would happen, because novices could not profit from the civil code since their lack of conceptual knowledge influences not only their interpretation of the case, but also their ability to use the civil code effectively. It could also be that novices lack knowledge of how the civil code is organized (e.g., were to find the right articles?, what does the numeration mean? etc.), or it might be a combination of both. The following examples of protocol excerpts illustrate nicely this. An example from an advanced student, who was not allowed to use the civil code, illustrates that without using the code, difficulties arise in reasoning about the right of reclamation "The right of reclamation..., well I do not know by heart what it exactly means...if I had the possibility to search in the civil code I would first look at the period of limitation...' The following example from a novice who could not use the civil code, seems similar, except that the advanced student is more specific in what 
(s)he would look for in the code: 'Oh no, I do not know what the definition of the right of retention is... I do not know what ownership exactly encompasses...I actually need a civil code to search for it...'. So both novice and advanced students indicate they need the code. However, when the civil code is available, the following example illustrates what happens when a novice starts searching for information, in this case also concerning the right of retention: 'The right of retention, hmm, I will look immediately at article 8. 945, hmm lets see 8. 945, I will go back.. hmm the code jumps from article 910 directly to 7, I first see article 908 and then $7.1 \mathrm{hmmm} \mathrm{ok}$, that is not what I am looking for...' This novice seems to experience problems finding the right information; (s)he does not know exactly what information (s)he is looking for and where it can be found. This is in marked contrast to the following excerpt from the protocol of an advanced student who could use the civil code, which illustrates that (s)he could not only find the right information regarding the right of reclamation, but could also link the information from the civil code to the information in the case regarding the claim: 'In this case $\mathrm{Mr}$ D has the right of reclamation because the civil code says: "that the owner of an object has the authority to claim the object from every person who keeps the object without permission"...'

\section{Reasoning process}

Furthermore it was found that novices who could use the civil code made significantly more regulative comments, $\mathrm{t}(55)=-3.30, \mathrm{p}<0.05, \mathrm{~d}=1.73$ than novices who could not use the civil code. This finding is probably due to the (ineffective) search processes in the civil code, and reflects "negative" remarks concerning regulation (e.g., 'I cannot find what I am looking for'). The following excerpt from a novice with the civil code illustrates that using the code leads to regulation even if the student has difficulties understanding the formal information: 'First I will search in the civil code what specifically is said about the right of retention, lets see hmm, ok, here it is said: "The right of retention means the authority, indicated by law, the creditor has to postpone the fulfilment of obligation until the claim is paid by the debtor"...well ok hmm, what does this all mean...?' Contrary to our expectations, there were no significant differences between advanced students who could and could not use the civil code both on regulation activities: $t(55)=-1.90$, ns, and execution activities: $t(55)=-1.07$, ns. So even though advanced students were able to benefit from the availability of the civil code in terms of accuracy, this did not seem to affect the amount of engagement in general reasoning processes, although it must have influenced the content.

\section{Conclusions and implications}

This study investigated the effects of the availability of conceptual knowledge on legal reasoning by comparing the accuracy and process of reasoning of students and experts when they could only rely on their knowledge. It was found that experts performed better than students, but that their performance was still rather low. This study provides an indication of the extent to which experts depend on information sources when reasoning about cases. They do not only seem to need such sources for substantiating conclusions, but also for working towards conclusions.

Next we investigated the effects of the availability of the civil code on the accuracy and process of novice and advanced students' legal reasoning. As we hypothesized, the availability of the civil code improved legal reasoning for advanced students, but not for novice students. Lack of conceptual knowledge and lack of knowledge of how information sources are organized, both by themselves or in combination, indeed seemed to lead to ineffective search processes when using the information sources. Such processes impose a high additional and ineffective (i.e., extraneous) load on working memory, that is, this load is not imposed by processes that contribute to the quality of the task performance (for a discussion of cognitive load theory, see Sweller et al., 1998; Van Merriënboer \& Sweller, 2005).

The findings strongly suggest that current instructional methods for novice students in law school are suboptimal. Law education relies heavily on the idea that students learn to reason about-and to solve-cases by engaging in solving cases (with the aid of external sources) from very early on in their trajectory. However, the results from the current study suggest that novices may learn very little from this form of instruction, that is, their performance does not seem to improve from being allowed to use the civil code compared to not having an information source available at all. Therefore, novice law students might need different forms of instruction, or more instructional guidance to help them learn to solve cases more effectively. Research on scaffolding or fading instructional guidance has shown that providing high levels of support initially (e.g., by reducing the amount of search required through the use of worked examples or by other means) and then slowly fading this out with increasing student expertise/knowledge, makes the learning process more effective and efficient (see e.g., Kalyuga et al., 2003; McNeill et al., 2006; Renkl \& Atkinson, 2003; Van Gog et al., 2008). Future studies should investigate whether forms of instructional guidance, such as scaffolding conceptual knowledge, 
or diminishing the additional cognitive load imposed by the search process in the civil code (e.g., by giving students not a full, but a condensed version containing only relevant information), are more effective and efficient for novices than the "traditional" method of instruction. Concerning scaffolding of conceptual knowledge, an important question is what the most optimal technique would be, and the answer likely depends on the type of concepts as well. It may be that providing the students with the definition of concepts suffices, however, the meaning of some legal concepts may vary according to the context (Lindahl, 2003; see also Nievelstein et al. in press), and learning these may therefore depend on repeated encounters with the concept in several different contexts and cases. In this case one might consider annotating concept definitions in different cases and requiring students to make comparisons between the meaning of the concepts in the cases.

It is impossible to imagine the law profession without the availability of external information sources, yet this study showed that the influence of these sources-and learning how to use them-on legal reasoning should not be underestimated. There is a difference between the way the profession is practiced and the way novices should be taught to become a practitioner in the domain. Even though the approaches to solving legal cases differ in Common Law and Civil Law, the current findings may also apply to the Common Law system. Conceptual knowledge plays an equally important role in Common Law, and even though the information sources used may differ (e.g., documented jurisprudence) the ineffectiveness of search processes when using these sources may not be that different. However, it would be interesting to test this in future studies.

Acknowledgements - The authors would like to thank Peter Slangen LL.M. for his judicial input, Dr. Lars van Vliet for the practical facilitation of this study, and Jeroen Janssen MSc. for his assistance with MEPA.

Appendix A-Civil law case

'The sailing boat'

Mister Schip (S) exploits a boat garaging. In a harbor lies the pilot of mister Schip of which he is the owner. March 1999, a wooden sailing boat (from now: the boat) is stolen from mister Duinstra (D). Mister D reported this theft by the police. September 2000, an unknown person requested mister $S$ to store a boat in his pilot; $S$ accepted and garaged the boat in his garaging. At the end of June, mister D sees by accident that his boat is stored in mister S' garaging, and he let $\mathrm{S}$ know that he is the owner of the boat. D requests $S$ to hand over the boat. $S$ is willing to do this on condition that $D$ pays the garaging costs. D refused. July, 25th 2004, D reported his discovery by the police. August the 1 st 2004, the police attached the boat and mister $\mathrm{S}$ is questioned as suspect of the theft by the police. October 30th 2004, the public prosecutor decided that the boat must be returned back to mister D.

Then this occurred. The criminal case against $S$ is dismissed by the public prosecutor because of insufficient valid evidence. December the 6th 2004, mister D is summonsed by mister S to appear in court. On the one hand, he claimed mister D to hand over the boat to him (S), on the other hand, conviction of $\mathrm{D}$ primary to pay the amount of $€ 3,600$, and secondary to a reasonable amount of finders' reward. Finally, S claims D in order to pay the legal costs. S founded this claim by stating that he has a right of action mattering the garaging costs of the boat as well as right of retention on the basis of which he has right to re-claim the boat.

How should you handle the case if you were mister D's lawyer?

\section{References}

Aamodt, A., \& Plaza, E. (1994). Case-based reasoning: Foundational issues methodological variations, and system approaches. AI Communications, 7, 39-59.

Bench-Capon, T. J. M., \& Visser, P. R. S. (1997). Ontologies in legal information systems: The need for explicit specifications of domain conceptualisations. In Proceedings of the Sixth International Conference on Artificial Intelligence and Law (pp. 132-141). New York: ACM Press.

Blasi, G. (1995). What lawyers know: Lawyering expertise, cognitive science, and the functions of theory. Journal of Legal Education, 45, 313-397.

Chi, M. T. H., \& Roscoe, R. D. (2002). The processes and challenges of conceptual change. In M. Limón \& L. Mason (Eds.), Reconsidering conceptual change. Issues in theory and practice (pp. 3-27). The Netherlands: Kluwer Academic.

Cowan, N. (2001). The magical number 4 in short term memory: A reconsideration of mental storage capacity. The Behavioral and Brain Sciences, 24, 87-185. doi:10.1017/S0140525X01003922. 
Deegan, D. H. (1995). Exploring individual differences among novices reading in a specific domain: The case of law. Reading Research Quarterly, 30, 154-170. doi:10.2307/748030.

Ericsson, K. A., \& Simon, H. A. (1993). Protocol analysis (3rd ed.). Cambridge: MIT Press.

Erkens, G. (2002). MEPA. Multiple episode protocol analysis (version 4.8) [computer software]. Utrecht, The Netherlands: Utrecht University.

Kalyuga, S., Ayres, P., Chandler, P., \& Sweller, J. (2003). The expertise reversal effect. Educational

Psychologist, 38, 23-32. doi:10.1207/S15326985EP3801_4.

Klomp, R. J. Q., \& Mak, C. (2005). Burgerlijk Wetboek 2005/2006 [Civil Code 2005/2006]. Nijmegen: Ars Aequi Libri.

Lindahl, L. (2003). Operative and justificatory grounds in legal argumentation. Associations, 7 , 185-200.

Lindahl, L. (2004). Deduction and justification in the law: The role of legal terms and concepts. Ratio Juris, 17, 182-202. doi:10.1111/j.1467-9337.2004.00263.x.

Lundeberg, M. A. (1987). Metacognitive aspects of reading comprehension: Studying understanding in case analysis. Reading Research Quarterly, 22, 407-432. doi: $10.2307 / 747700$.

Marchant, G., Robinson, J., Anderson, U., \& Schadewald, M. (1993). The use of analogy in legal argument: Problem similarity, precedent, and expertise. Organizational Behavior and Human Decision Processes, 55, 95-119. doi:10.1006/obhd.1993.1026.

McNeill, K. L., Lizotte, D. J., Krajcik, J., \& Marx, R. W. (2006). Supporting students' construction of scientific explanations by fading scaffolds in instructional materials. Journal of the Learning Sciences, 15, 153-191. doi:10.1207/s15327809jls1502_1.

Miller, G. A. (1956). The magical number seven, plus or minus two: Some limits on our capacity for processing information. Psychological Review, 63, 81-97. doi:10.1037/h0043158.

Nievelstein, F., Boshuizen, H. P. A., Van Bruggen, J. M., \& Prins, F. J. (2005). The role of knowledge development and ontological change in the development of expertise in legal reasoning; toward a domain model. Paper presented at the European Association for Research on Learning and Instruction (EARLI), Cyprus.

Nievelstein, F., Van Gog, T., Boshuizen, H. P. A., \& Prins, F. J. (in press). Expertise-related differences in ontological and conceptual knowledge development in the legal domain. The European Journal of Cognitive Psychology.

Oates, L. C. (2006). Leveling the playing field: Helping students succeed by helping them learn to read as expert lawyers. St John's Law Review, 80, 227-255.

Renkl, A., \& Atkinson, R. K. (2003). Structuring the transition from example study to problem solving in cognitive skills acquisition: A cognitive load perspective. Educational Psychologist, 38, 15-22. doi:10.1207/S15326985EP3801_3.

Slotta, J. D., \& Chi, M. T. H. (2006). Helping students understand challenging topics in science through ontology training. Cognition and Instruction, 24, 261-289. doi:10.1207/s1532690xci2402_3.

Stratman, J. F. (2002). When law students read cases: Exploring relations between professional legal reasoning roles and problem detection. Discourse Processes, 34, 57-90. doi:10.1207/S15326950DP3401_3.

Stratman, J. F. (2004). How Legal analysts negotiate indeterminacy of meaning in common law rules: Toward a synthesis of linguistic and cognitive approaches to investigation. Language \& Communication, 24, 23-57. doi:10.1016/S0271-5309(02)00041-1.

Sullivan, M. W., Colby, A., Welch-Wegner, J., Bond, L., \& Shulman, L. S. (2007). Educating lawyers. San Francisco: Jossey-Bass.

Sweller, J., Van Merrienboer, J. J. G., \& Paas, F. (1998). Cognitive architecture and instructional design. Educational Psychology Review, 10, 251-296. doi:10.1023/A:1022193728205.

Toulmin, S. E., Rieke, R., \& Janik, A. (1984). An introduction to reasoning. New York: Macmillan.

Van Gog, T., Paas, F., \& Van Merriënboer, J. J. G. (2008). Effects of studying sequences of processoriented and product-oriented worked examples on troubleshooting transfer efficiency. Learning and Instruction, 18, 211-222. doi:10.1016/j.learninstruc.2007.03.003.

Van Merriënboer, J. J. G., \& Sweller, J. (2005). Cognitive load theory and complex learning: Recent developments and future directions. Educational Psychology Review, 17, 147-177. doi:10.1007/ s10648-005-3951-0.

Van Someren, M. W., Barnard, Y. F., \& Sandberg, J. A. C. (1994). The think aloud method: A practical guide to modeling cognitive processes. London: Academic Press.

Vandevelde, K. J. (1996). Thinking like a lawyer: An introduction to legal reasoning. Colorado: 


\section{Westview Press.}

Veenman, M. V. J., \& Elshout, J. J. (1995). Differential effects of instructional support on learning in simulation environments. Instructional Science, 22, 363-383. doi:10.1007/BF00891961.

Williams, S. M. (1992). Putting case-based instruction into context: Examples from legal and medical education. Journal of the Learning Sciences, 2, 367-427.

doi:10.1207/s15327809jls0204_2. 